\title{
In situ UV-Visible Spectroscopic Measurements of Kinetic Parameters and Active Sites for Catalytic Oxidation of Alkanes on Vanadium Oxides ${ }^{\dagger}$
}

\author{
Morris D. Argyle, $\$$ Kaidong Chen, ${ }^{\S}$ Enrique Iglesia,* and Alexis T. Bell* \\ Chemical Sciences Division, E.O. Lawrence Berkeley National Laboratory and \\ Department of Chemical Engineering, University of California, Berkeley, California 94720-1462
}

Received: March 30, 2004

\begin{abstract}
In situ diffuse reflectance UV-visible spectroscopy was used to measure the dynamics of catalyst reduction and oxidation during propane oxidative dehydrogenation $(\mathrm{ODH})$ on $\mathrm{VO}_{x} / \gamma-\mathrm{Al}_{2} \mathrm{O}_{3}$. Transients in $\mathrm{UV}-$ visible intensity in the near-edge region were analyzed using a mechanistic model of ODH reactions. Rate constants per site for the kinetically relevant reduction step $(\mathrm{C}-\mathrm{H}$ bond activation) measured using this analysis are slightly larger than those obtained from steady-state ODH rates normalized by surface $\mathrm{V}$. The ratio of these values provides a measure of the fraction of the $\mathrm{V}$ surface sites that are active for ODH $(0.6-0.7$, for $\mathrm{V}$ surface densities of $2.3-34 \mathrm{~V} \mathrm{~nm}^{-2}$ ). This suggests that some of the $\mathrm{V}$ atoms are either inaccessible or inactive. Reoxidation rate constants, which cannot be obtained from steady-state analysis, are $10^{3}-10^{5}$ times larger than those for the $\mathrm{C}-\mathrm{H}$ bond activation reduction step.
\end{abstract}

\section{Introduction}

Diffuse reflectance UV-visible spectroscopy is a useful probe of the electronic structure of dispersed metal oxides. ${ }^{1-8} \mathrm{~A}$ number of studies have shown that in situ UV-visible spectroscopy can probe the extent of reduction under steady-state catalysis. $^{9-20}$ Few studies have explored in situ transientresponse methods using $\mathrm{UV}-$ visible spectroscopy for the purpose of determining kinetic parameters for elementary steps. $^{21-23}$ Also, none of the reported work has examined the reduction and oxidation cycles that occur during the oxidative dehydrogenation $(\mathrm{ODH})$ of alkanes, a reaction that proceeds via a Mars-van Krevelen redox cycle using lattice oxygen atoms in metal oxides. ${ }^{1-4,24-30}$

In this study, we report the use of UV-visible spectroscopy in a transient mode to study the dynamics of redox cycles for catalytically active centers involved in propane $\mathrm{ODH}$ on alumina-supported vanadia catalysts. The analysis of these data leads to the determination of the rate coefficients for the reduction and reoxidation of active centers. Since the first of these rate coefficients can also be obtained from steady-state data, it is possible to assess the fraction of the exposed $\mathrm{V}$ sites that are active for ODH. The rate coefficient for site reoxidation is also provided by the transient-response UV-visible data; it is not available from steady-state rate measurements.

\section{Experimental Section}

$\mathrm{VO}_{x} / \mathrm{Al}_{2} \mathrm{O}_{3}$ catalysts were prepared by incipient wetness impregnation of $\gamma$-alumina (Degussa, A. G., $100 \mathrm{~m}^{2} / \mathrm{g}$ ) with

\footnotetext{
† Part of the special issue "Michel Boudart Festschrift".

* Authors to whom correspondence should be addressed. E-mail: bell@cchem.berkeley.edu (A.T.B.); iglesia@cchem.berkeley.edu (E.I.).

$\doteqdot$ Current address: University of Wyoming, Department of Chemical and Petroleum Engineering, Department 3295, 1000 E. University Avenue, Laramie, WY 82071.

$\S$ Current address: Chevron-Texaco Research and Technology Company, 100 Chevron Way, Richmond, CA 94802.
}

aqueous solutions of ammonium metavanadate (99\%, Aldrich, Inc.) and oxalic acid (Mallinckrodt A. G.) (1:2 by weight, $\mathrm{pH}$ 2). The impregnated samples were dried, crushed, treated in dry air at $773 \mathrm{~K}$, and ground into fine powders $(45-100 \mu \mathrm{m})$ using a mortar and pestle. Details of the catalyst synthesis procedure and structural characterization data are reported elsewhere. ${ }^{2-4}$ Three $\mathrm{V}_{2} \mathrm{O}_{5} / \gamma-\mathrm{Al}_{2} \mathrm{O}_{3}$ samples with $3.5,10$, and $30 \mathrm{wt} \% \mathrm{~V}_{2} \mathrm{O}_{5}$ and vanadia surface densities of $2.3,8.0$, and 34 $\mathrm{V} \mathrm{nm}{ }^{-2}$, respectively, were used in this study. ${ }^{2,3}$ Before each experiment, samples were treated at $773 \mathrm{~K}$ in $5 \% \mathrm{O}_{2}$ (Airgas, 99.999\%), in He (Airgas, 99.999\%), or in $\mathrm{Ar}$ (Airgas, 99.999\%). UV-visible and Raman spectroscopic studies showed that 3.5 wt $\% \mathrm{~V}_{2} \mathrm{O}_{5} / \mathrm{Al}_{2} \mathrm{O}_{3}\left(2.3 \mathrm{~V} \mathrm{~nm}^{-2}\right)$ contains predominantly isolated monovanadate species, $10 \mathrm{wt} \% \mathrm{~V}_{2} \mathrm{O}_{5} / \mathrm{Al}_{2} \mathrm{O}_{3}\left(8.0 \mathrm{~V} \mathrm{~nm}^{-2}\right)$ consists of polyvanadate domains coexisting with trace amounts of $\mathrm{V}_{2} \mathrm{O}_{5}$ crystallites, and $30 \mathrm{wt} \% \mathrm{~V}_{2} \mathrm{O}_{5} / \mathrm{Al}_{2} \mathrm{O}_{3}\left(34 \mathrm{~V} \mathrm{~nm}{ }^{-2}\right)$ contains large $\mathrm{V}_{2} \mathrm{O}_{5}$ crystallites. ${ }^{2,3}$

UV-visible spectra were collected using a Cary 4 Varian spectrophotometer with a Harrick Scientific diffuse reflectance attachment (DRP-XXX) and a reaction chamber (DRA-2CR). The reactor cell was modified with a quartz frit to support samples in order to improve flow uniformity. A kinetic spectrophotometer mode was used to collect UV-visible spectra by monitoring the intensity at a single energy $(1.86 \mathrm{eV})$ in the preedge region of transient responses with a time resolution of $0.1-1 \mathrm{~s}$ during propane $\mathrm{ODH}$ after abrupt changes in $\mathrm{O}_{2}$ or $\mathrm{C}_{3} \mathrm{H}_{8}$ concentrations.

Total flow rates were kept at $1.67 \mathrm{~cm}^{3} \mathrm{~s}^{-1}$ using mass flow controllers (Porter Instrument) for individual $\mathrm{C}_{3} \mathrm{H}_{8} / \mathrm{Ar}, \mathrm{O}_{2} / \mathrm{Ar}$ or $\mathrm{O}_{2} / \mathrm{He}$, and $\mathrm{Ar}$ streams in order to achieve the desired concentrations of each reactant. These flow rates corresponded to a space velocity of $50 \mathrm{~cm}^{3} \mathrm{~s}^{-1} \mathrm{~g}^{-1}$ for catalyst amounts used in this study $(\sim 30 \mathrm{mg})$. Rapid switches between one reactant composition and another were made using an electrically actuated four-way valve (Valco Instruments Company). The reaction temperature was held at $603 \mathrm{~K}$ and treatments in $\mathrm{O}_{2-}$ 


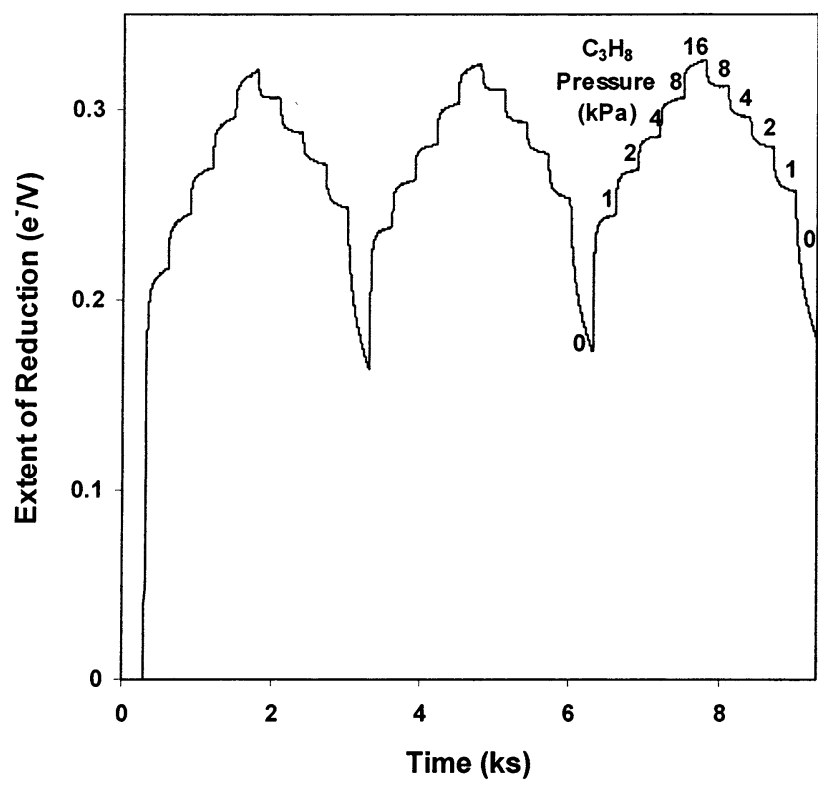

Figure 1. Extent of reduction during step changes in $\mathrm{C}_{3} \mathrm{H}_{8}$ concentration of $300 \mathrm{~s}$ duration, starting from the fully oxidized catalyst [10 wt $\% \mathrm{~V}_{2} \mathrm{O}_{5} / \mathrm{Al}_{2} \mathrm{O}_{3}\left(8.0 \mathrm{~V} \mathrm{~nm}{ }^{-2}\right), 603 \mathrm{~K}, 4.0 \mathrm{kPa} \mathrm{O}$, each cycle progresses through $0,1.0,2.0,4.0,8.0,16,8.0,4.0,2.0,1.0 \mathrm{kPa} \mathrm{C}_{3} \mathrm{H}_{8}$, balance $\mathrm{Ar}, 603 \mathrm{~K}]$. Adapted from ref 20.

containing streams were carried out at $773 \mathrm{~K}$ to re-oxidize samples. A thermocouple located within the catalyst bed was used to measure local temperatures; another thermocouple inserted within the heater beneath the sample holder recorded temperatures as much as $100 \mathrm{~K}$ above sample temperatures, as previously reported. ${ }^{9}, 11$ Propane $\mathrm{ODH}$ experiments were conducted at $603 \mathrm{~K}$ using $\mathrm{C}_{3} \mathrm{H}_{8}$ (Airgas, 99.9\%) and $\mathrm{O}_{2}$ (Airgas, 99.99\%) reactants diluted to the desired partial pressures with Ar (Airgas, 99.999\%). Partial pressures for each reactant were varied independently from 1.0 to $16 \mathrm{kPa}$, while keeping the other reactant at $4.0 \mathrm{kPa}$; the intervals between composition changes were $300 \mathrm{~s}$.

\section{Results and Discussion}

UV-visible measurements were carried out during transient ODH reaction conditions. The experiments were carried out using a catalyst treated for $300 \mathrm{~s}$ of exposure to $4.0 \mathrm{kPa} \mathrm{O}_{2}$. The inlet stream was then switched to one containing $\mathrm{C}_{3} \mathrm{H}_{8}$ and $\mathrm{O}_{2}$ for $300 \mathrm{~s}$. The partial pressure of one of the reactants was held constant for the duration of the ODH experiment, while the other was varied every $300 \mathrm{~s}$. Absorption intensities (at $1.86 \mathrm{eV}$ ) were converted to extent of reduction and the catalytically irrelevant portion of the measured absorbance was excluded using methods previously reported. ${ }^{19,20}$ Figure 1 , which was adapted from a previous publication, ${ }^{20}$ shows reduction transients resulting from step-wise changes in $\mathrm{C}_{3} \mathrm{H}_{8}$ pressure at constant $\mathrm{O}_{2}$ pressure; each cycle feed composition cycle was followed by a treatment in 4 $\mathrm{kPa} \mathrm{O}_{2}$ at $603 \mathrm{~K}$ for $300 \mathrm{~s}$. Results similar to those shown in Figure 1 were obtained with $\mathrm{O}_{2}$ partial-pressure cycles (not shown). In this latter case, the experiment was started by switching from a stream containing $4 \mathrm{kPa} \mathrm{O}_{2}$ to one consisting of $16 \mathrm{kPa} \mathrm{O} 2$ and $4 \mathrm{kPa}$ of $\mathrm{C}_{3} \mathrm{H}_{8}$.

As noted previously, ${ }^{20}$ transient responses, such as those shown in Figure 1, contain two components-a rapid response with a time-scale of catalytic turnovers $(<1000 \mathrm{~s})$ and a significantly slower process, which reflects changes in the structure of the vanadia domains or oxygen removal from the internal crystalline region, without direct relevance to the dynamics of catalytic turnovers. The procedure described previously ${ }^{20}$ was used to isolate the portion of each transient that reflects catalytically relevant processes. The resulting transients are shown in Figures 2-4. We note that transients involving increasing or decreasing concentrations were identical, except for the sign of the transient, and that repeated transients were highly reproducible.

The observed transient responses were fitted to the time dependence of the concentration of reduced centers derived from a previously reported mechanism of ODH processes, ${ }^{29,30}$ modified to account for combustion pathways (Scheme 1, reactions $1-5)$. The concentrations of four surface intermediates in the mechanism were considered initially: oxygen $\left(\left[\mathrm{O}^{*}\right]\right)$, vacancies $([*])$, hydroxyl groups $\left(\left[\mathrm{OH}^{*}\right]\right)$, and isopropoxide species $\left(\left[\mathrm{C}_{3} \mathrm{H}_{7} \mathrm{O}^{*}\right]\right)$. The combustion steps were not analyzed in detail, as indicated by the ellipsis in reactions $3 \mathrm{a}$ and $3 \mathrm{~b}$. The sequence of elementary steps leading to combustion products ultimately results in the formation of the number of reduced-surface species shown in reactions $3 \mathrm{a}$ and $3 \mathrm{~b}$. These steps are known to involve surface oxygen and reduced-surface species because lattice oxygen atoms from the catalyst are incorporated in all combustion products, as shown by isotopic labeling studies. ${ }^{29-31}$ The first step was assumed to be quasi-equilibrated with a small $K_{1}$ value. Consequently, the concentration of physisorbed propane $\left[\left(\mathrm{C}_{3} \mathrm{H}_{8} \mathrm{O}^{*}\right]\right)$ can be neglected in the site balance. Step 2 is the kinetically relevant step, ${ }^{29-30}$ and rate constants of subsequent steps are, therefore, inaccessible from steady-state rate data.

A set of coupled, nonlinear differential equations were derived to described the time-dependent response of the surface species. $^{31}$ These equations were then non-dimensionalized using the ratio of each surface species concentration to the total concentration of active surface sites ([L]). Thus, $\chi=\left[\mathrm{OH}^{*}\right] /$ $[\mathrm{L}], \phi=[*] /[\mathrm{L}], \theta=\left[\mathrm{C}_{3} \mathrm{H}_{7} \mathrm{O}^{*}\right] /[\mathrm{L}], \psi=\left[\mathrm{O}^{*}\right] /[\mathrm{L}]$, and $\chi+\phi$ $+\theta+\psi=1$. As a result, only three of the differential equations are independent, and the time-dependent response of the fourth surface species may be obtained from this overall site balance. The three differential equations describing the surface-reduced species and the algebraic equation representing the fraction of surface oxygen, derived from the site balance, are given by eqs $1-4$. A derivation of these equations is given in ref 31 .

$$
\begin{gathered}
\frac{\mathrm{d} \chi}{\mathrm{d} \tau}=(1-\chi-\theta-\phi)^{2}+\lambda_{1} \frac{\epsilon_{1}}{\left[\mathrm{C}_{3} \mathrm{H}_{8}\right]} \theta-2 \frac{\epsilon_{2}}{\left[\mathrm{C}^{3} \mathrm{H}_{8}\right]} \chi^{2}+ \\
2 \epsilon_{3} \frac{\left[\mathrm{H}_{2} \mathrm{O}\right]}{\left[\mathrm{C}_{3} \mathrm{H}_{8}\right]}(1-\chi-\theta-\phi) \phi \\
\frac{\mathrm{d} \theta}{\mathrm{d} \tau}=(1-\chi-\theta-\phi)^{2}-\frac{\epsilon_{1}}{\left[\mathrm{C}_{3} \mathrm{H}_{8}\right]} \theta \\
\frac{\mathrm{d} \phi}{\mathrm{d} \tau}=\lambda_{2} \frac{\epsilon_{1}}{\left[\mathrm{C}_{3} \mathrm{H}_{8}\right]} \theta+\frac{\epsilon_{2}}{\left[\mathrm{C}_{3} \mathrm{H}_{8}\right]} \chi_{2}-\epsilon_{3} \frac{\left[\mathrm{H}_{2} \mathrm{O}\right]}{\left[\mathrm{C}_{3} \mathrm{H}_{8}\right]}(1-\chi-\theta- \\
\phi) \phi-2 \epsilon_{4} \frac{\left[\mathrm{O}_{2}\right]}{\left[\mathrm{C}_{3} \mathrm{H}_{8}\right]} \phi^{2} \\
\psi=1-\chi-\theta-\phi
\end{gathered}
$$

The dimensionless reduced time, $\tau$, is defined as the actual time divided by the characteristic time for the kinetically relevant $\mathrm{C}-\mathrm{H}$ bond activation step:

$$
\tau=\frac{t}{\tau_{\mathrm{r}}}=K_{1} k_{2}\left[\mathrm{C}_{3} \mathrm{H}_{8}\right] t
$$



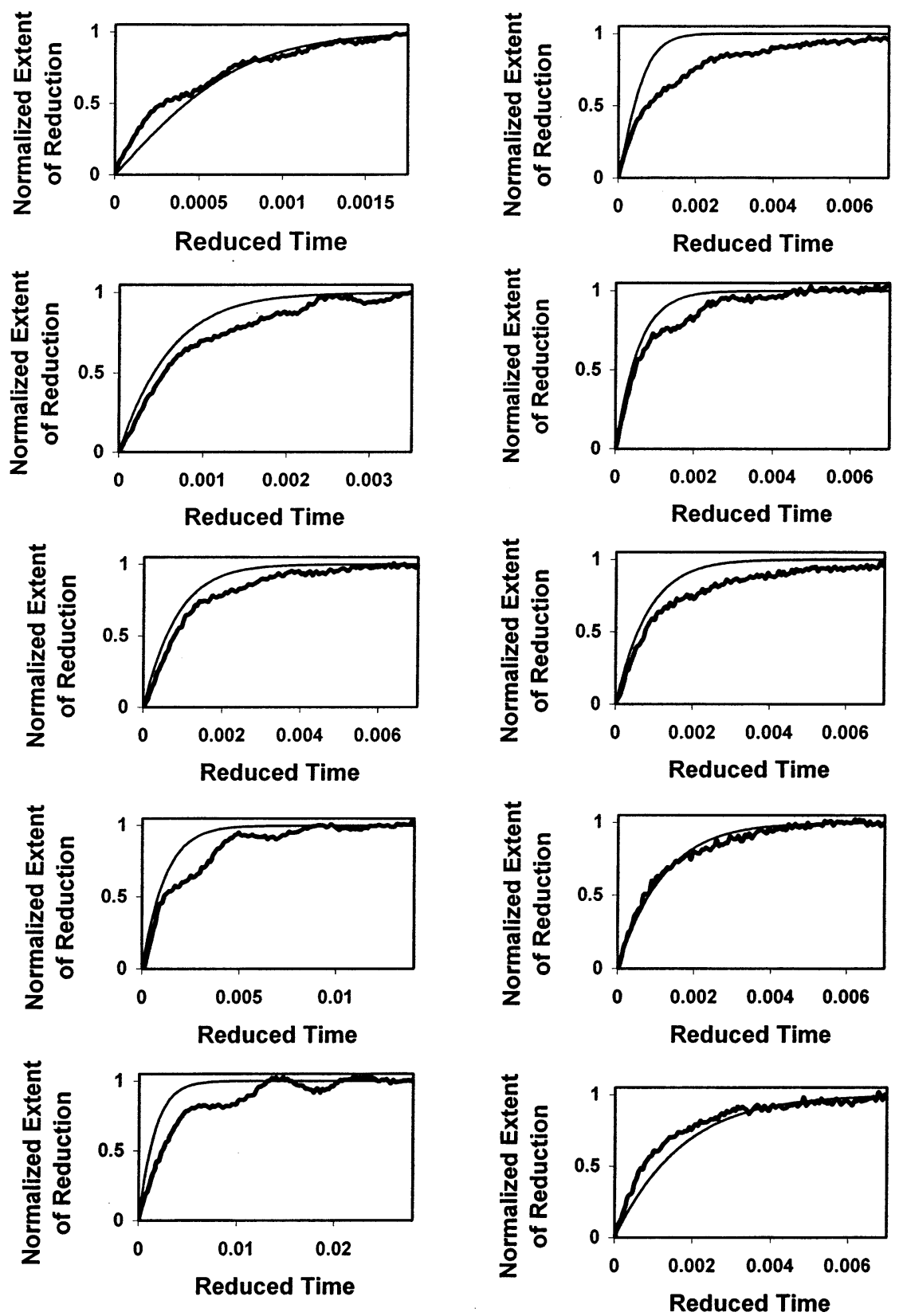

Figure 2. Experimental data (heavy lines) compared with the simplified model results (light lines) for normalized extent of reduction response during 300 s transients. Figure $2 \mathrm{a}-\mathrm{e}$ are $\mathrm{C}_{3} \mathrm{H}_{8}$ concentration transients [(a) 1.0, (b) 2.0, (c) 4.0, (d) 8.0, and (e) $16 \mathrm{kPa} \mathrm{C}_{3} \mathrm{H}_{8}$ at $4.0 \mathrm{kPa} \mathrm{O}_{2}$ ]. Figure $2 \mathrm{f}-\mathrm{j}$ are $\mathrm{O}_{2}$ concentration transients [(f) 16 , (g) 8.0, (h) 4.0, (i) 2.0 , and (j) $1.0 \mathrm{kPa} \mathrm{O}$ at $\left.4.0 \mathrm{kPa} \mathrm{C}_{3} \mathrm{H}_{8}\right]$. [3.5 wt $\% \mathrm{~V}_{2} \mathrm{O}_{5} / \mathrm{Al}_{2} \mathrm{O}_{3}\left(2.3 \mathrm{~V} \mathrm{~nm}{ }^{-2}\right), 603$ $\mathrm{K}]$.

The other four parameters, $\epsilon_{i}$, are defined as

$$
\epsilon_{1}=\frac{k_{3}}{k_{2} K_{1}} \quad \epsilon_{2}=\frac{k_{-4}}{k_{2} K_{1}} \quad \epsilon_{3}=\frac{k_{4}}{k_{2} K_{1}} \quad \epsilon_{4}=\frac{k_{5}}{k_{2} K_{1}}
$$

The factors $\lambda_{i}$ are defined as

$$
\begin{gathered}
\lambda_{1}=7-6 x_{1} \\
\lambda_{2}=3\left(2-2 x_{1}-x_{2}\right)
\end{gathered}
$$

where $x_{1}$ and $x_{2}$ are the fractional selectivities to propene and $\mathrm{CO}$, respectively.

The numerical solution of eqs $1-4$ was fitted to the transient response data shown in Figures $2-4$ by adjusting the values of $k_{2} K_{1}, k_{3}, k_{4}, k_{-4}$, and $k_{5}$. The reactant concentrations used in eqs $1-4$ were those prevailing during the transient. Since the conversions of $\mathrm{C}_{3} \mathrm{H}_{8}$ and $\mathrm{O}_{2}$ were small $(<1 \%$ and $<5 \%$, respectively), inlet concentrations were used. The water concentration during the transient could not be reliably measured by mass spectroscopy; instead, it was calculated based on the stoichiometric amount expected for the observed concentrations of propene, $\mathrm{CO}$, and $\mathrm{CO}_{2}$. Since steady-state observations showed the selectivity to $\mathrm{C}_{3} \mathrm{H}_{6}$ and $\mathrm{CO}$ to be nearly independent of feed composition at low reactant conversions, the values of $x_{1}$ and $x_{2}$ were taken to be constant (see Table 1). ${ }^{2,3}$

The extent of reduction, defined as the number of one-electron reduced centers per $\mathrm{V}$ atom $\left(n_{\mathrm{r}}\right)$, was calculated by adding the fractional coverages of all reduced species after doubling vacancy concentrations, which represent two-electron reduction events (eq 8). The parameters $\tau_{\mathrm{r}}$ and $\epsilon_{i}$ were obtained using

$$
n_{\mathrm{r}}=\chi+\theta+2 \phi
$$



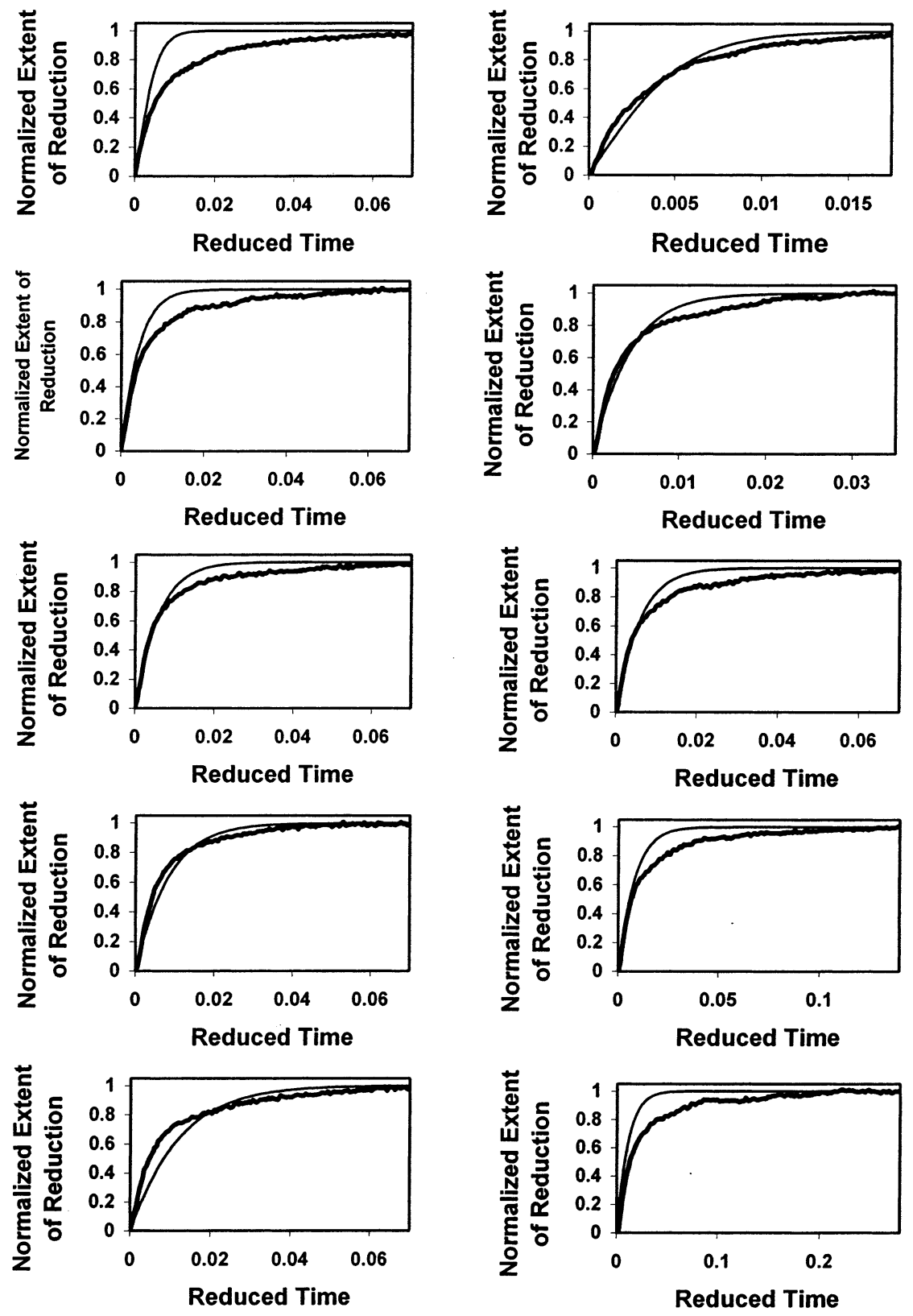

Figure 3. Experimental data (heavy lines) compared with the simplified model results (light lines) for normalized extent of reduction response during $300 \mathrm{~s}$ transients. Figure $3 \mathrm{a}-\mathrm{e}$ are $\mathrm{C}_{3} \mathrm{H}_{8}$ concentration transients [(a) 1.0, (b) 2.0, (c) 4.0, (d) 8.0, and (e) $16 \mathrm{kPa} \mathrm{C}_{3} \mathrm{H}_{8}$ at $4.0 \mathrm{kPa} \mathrm{O}$. Figure $3 \mathrm{f}-\mathrm{j}$ are $\mathrm{O}_{2}$ concentration transients [(f) 16, (g) 8.0, (h) 4.0, (i) 2.0 , and (j) $1.0 \mathrm{kPa} \mathrm{O}$ at $\left.4.0 \mathrm{kPa} \mathrm{C}_{3} \mathrm{H}_{8}\right] .\left[10 \mathrm{wt} \% \mathrm{~V}_{2} \mathrm{O}_{5} / \mathrm{Al}_{2} \mathrm{O}_{3}\left(8.0 \mathrm{~V} \mathrm{~nm}{ }^{-2}\right), 603\right.$ $\mathrm{K}]$.

standard nonlinear regression techniques in Mathematica 4.0. The initial values of $\tau_{\mathrm{r}}$ and $\epsilon_{i}$ were varied over 8 orders of magnitude to ensure that the chosen parameters corresponded to global error minima in the estimation procedure.

These methods of analysis indicate that vacancies are the predominant reduced species $(\phi=[*] /[\mathrm{L}]=0.05$ at $16 \mathrm{kPa}$ $\mathrm{C}_{3} \mathrm{H}_{8}, 4 \mathrm{kPa} \mathrm{O}$ on $10 \mathrm{wt} \% \mathrm{~V}_{2} \mathrm{O}_{5} / \mathrm{Al}_{2} \mathrm{O}_{3}$ ) at the low-waterconcentration conditions prevalent in this study. The same conclusion was drawn from steady-state reaction rates. ${ }^{19,20}$ Vacancies account for most ( $>90 \%$ ) of the reduced species for all catalysts and reactant ratios. Consistent with this, the best fit of the model to the data was insensitive to the values of $\epsilon_{1}$, $\epsilon_{2}$, and $\epsilon_{3}$. The insensitivity of the model to the value of $\epsilon_{1}$ suggests that isoproproxide conversion rate constants are significantly larger than those for its formation; hence, $\theta$ reaches steady-state more rapidly than $n_{\mathrm{r}}$. In agreement with this conclusion, the steady-state values of $\theta$ are small, e.g., $\theta<4$ $\times 10^{-4}$ at $16 \mathrm{kPa} \mathrm{C}_{3} \mathrm{H}_{8}, 4 \mathrm{kPa} \mathrm{O}$ on $10 \mathrm{wt} \% \mathrm{~V}_{2} \mathrm{O}_{5} / \mathrm{Al}_{2} \mathrm{O}_{3}$. The insensitivity of the model to the value of $\epsilon_{2}$ and $\epsilon_{3}$ suggests that water-formation steps are quasi-equilibrated, as assumed in previous mechanistic analyses and confirmed by kinetic and isotopic tracer studies. ${ }^{29-32}$ The steady-state values of $\chi$ are also small (e.g., $\chi<0.003$ at $16 \mathrm{kPa} \mathrm{C}_{3} \mathrm{H}_{8}, 4 \mathrm{kPa} \mathrm{O}$ on $10 \mathrm{wt} \%$ $\mathrm{V}_{2} \mathrm{O}_{5} / \mathrm{Al}_{2} \mathrm{O}_{3}$ ). The small values of $\theta$ and $\chi$ lead to a simple expression for the concentration of reduced centers (eq 9):

$$
n_{\mathrm{r}} \cong 2 \phi
$$

The model was then simplified by applying the pseudosteady-state hypothesis to $\theta$ and $\chi\left(\left[\mathrm{C}_{3} \mathrm{H}_{7} \mathrm{O}^{*}\right] /[\mathrm{L}]\right.$ and $\left[\mathrm{OH}^{*}\right] /$ [L], respectively), which implies that the derivatives of $\theta$ and $\chi$ with respect to $\tau$ are small and do not vary significantly with 

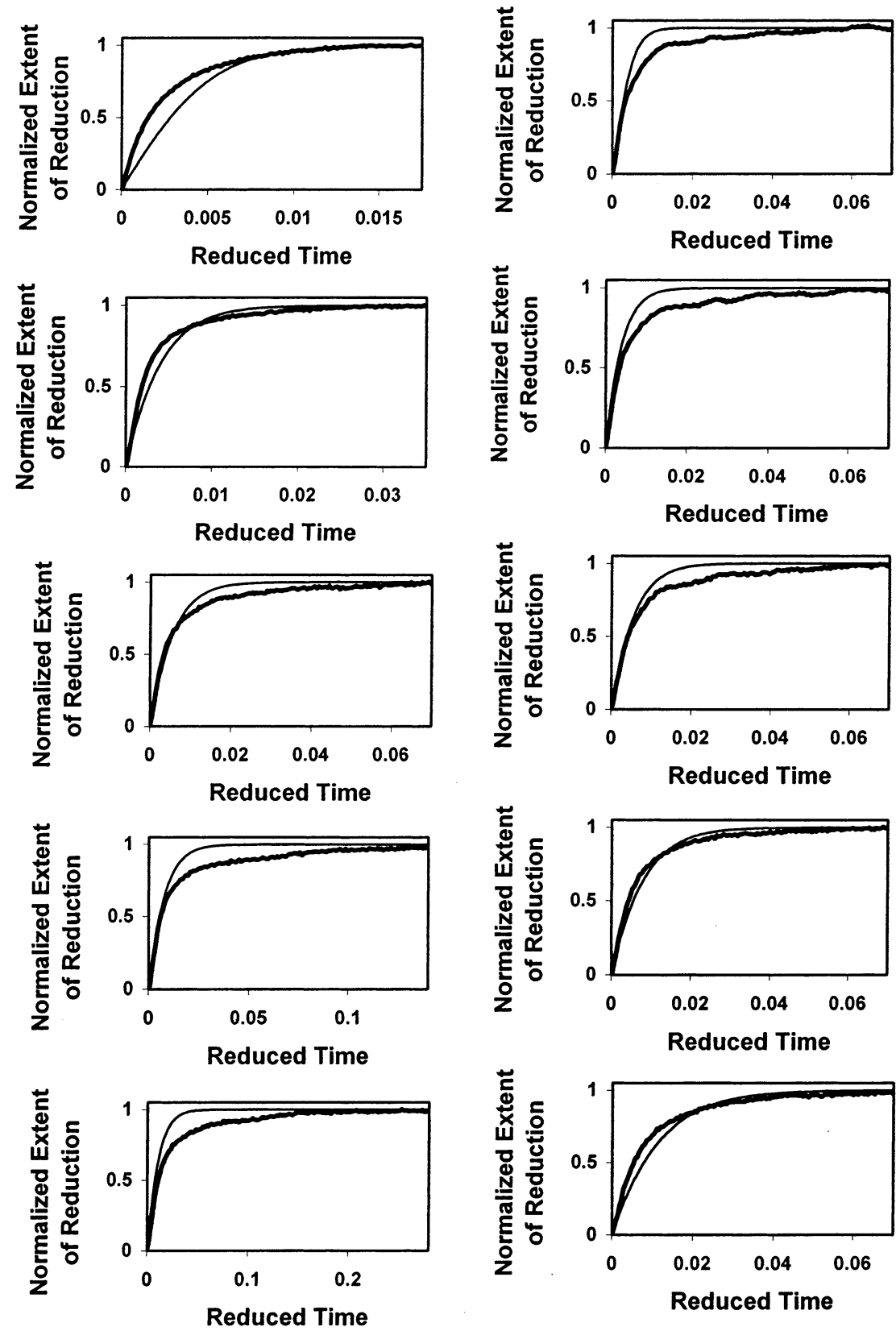

Figure 4. Experimental data (heavy lines) compared with the simplified model results (light lines) for normalized extent of reduction response during $300 \mathrm{~s}$ transients. Figure $4 \mathrm{a}-\mathrm{e}$ are $\mathrm{C}_{3} \mathrm{H}_{8}$ concentration transients [(a) 1.0, (b) 2.0, (c) 4.0 , (d) 8.0 , and (e) $16 \mathrm{kPa} \mathrm{C}_{3} \mathrm{H}_{8}$ at $4.0 \mathrm{kPa} \mathrm{O}_{2}$ ]. Figure $4 \mathrm{f}-\mathrm{j}$ are $\mathrm{O}_{2}$ concentration transients [(f) 16 , (g) 8.0, (h) 4.0, (i) 2.0, and (j) $1.0 \mathrm{kPa} \mathrm{O}$ at $\left.4.0 \mathrm{kPa} \mathrm{C}_{3} \mathrm{H}_{8}\right] .\left[30 \mathrm{wt}_{2} \mathrm{~V}_{2} \mathrm{O}_{5} / \mathrm{Al}_{2} \mathrm{O}_{3}\left(34 \mathrm{~V} \mathrm{~nm}{ }^{-2}\right), 603\right.$ $\mathrm{K}]$.

TABLE 1: Initial Propane ODH Selectivities to $\mathrm{C}_{3} \mathrm{H}_{6}\left(x_{1}\right)$, $\mathrm{CO}\left(x_{2}\right)$, and $\mathrm{CO}_{2}\left(x_{3}\right)$ Obtained from Steady-State ODH Experiments $^{2, a}$

\begin{tabular}{|c|c|c|c|}
\hline $\begin{array}{c}\text { catalyst } \\
\left(\mathrm{wt} \% \mathrm{~V}_{2} \mathrm{O}_{5}\right. \\
\left.\text { on } \mathrm{Al}_{2} \mathrm{O}_{3}\right)\end{array}$ & $\begin{array}{c}\mathrm{C}_{3} \mathrm{H}_{6} \\
\text { selectivity } \\
\left(x_{1}\right)\end{array}$ & $\begin{array}{c}\mathrm{CO} \\
\text { selectivity } \\
\left(x_{2}\right)\end{array}$ & $\begin{array}{c}\mathrm{CO}_{2} \\
\text { selectivity } \\
\left(x_{3}\right)\end{array}$ \\
\hline 3.5 & 0.85 & 0.086 & 0.064 \\
\hline 10 & 0.84 & 0.11 & 0.05 \\
\hline 30 & 0.74 & 0.19 & 0.07 \\
\hline
\end{tabular}

${ }^{a} 603 \mathrm{~K}, 14 \mathrm{kPa} \mathrm{C} \mathrm{H}_{8}, 1.7 \mathrm{kPa} \mathrm{O}$, balance $\mathrm{He}$.

time in the time scale of the transient response of turnover rates for the entire catalytic sequence. Since steady-state $\phi$ values are small $(<0.05), \psi$ was taken to be $\sim 1.0$. With these simplifying assumptions, the time-dependent response of the

\section{SCHEME 1}

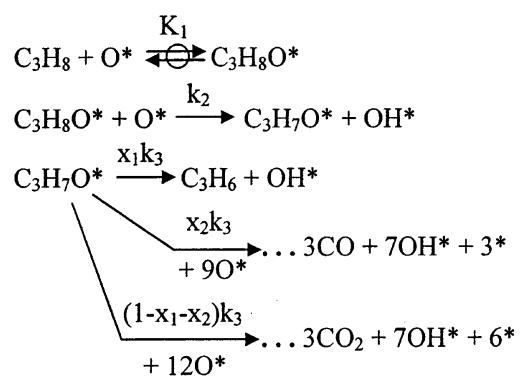

$2 \mathrm{OH}^{*} \underset{\mathrm{k}_{4}}{\stackrel{\mathrm{k}_{-4}}{\rightleftarrows}} \mathrm{H}_{2} \mathrm{O}+\mathrm{O}^{*}+*$

$\mathrm{O}_{2}+2 * \stackrel{\mathrm{k}_{5}}{\longrightarrow} \mathrm{O}^{*}+\mathrm{O}^{*}$ 


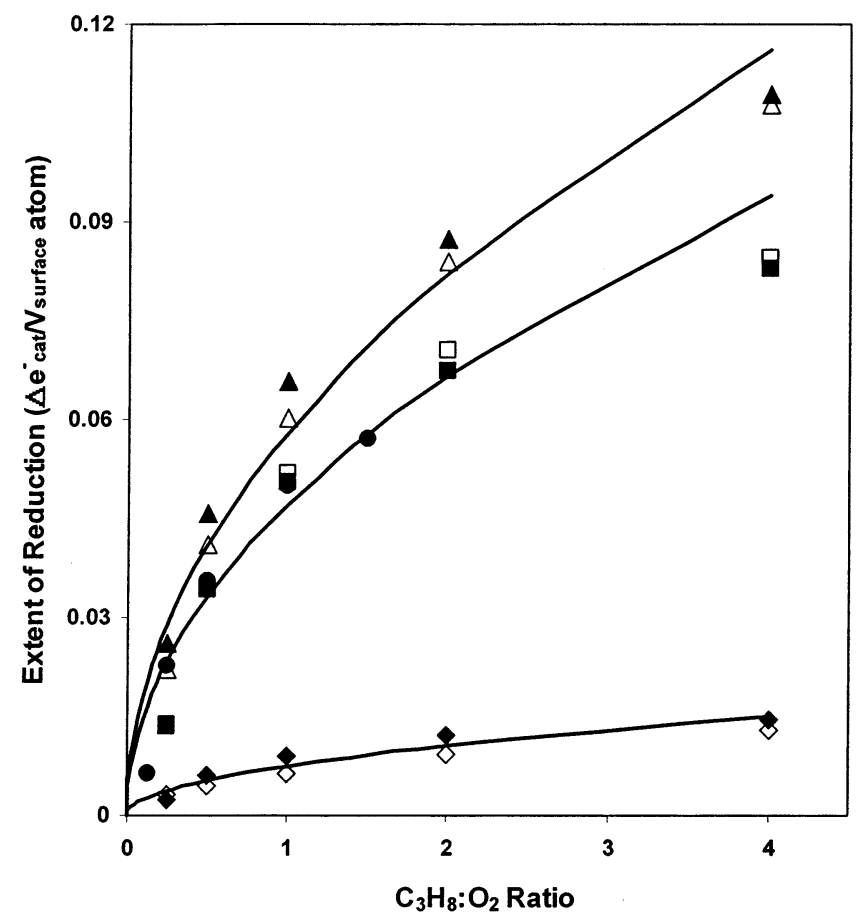

Figure 5. Dependence of the extent of catalytically relevant reduction per surface $\mathrm{V}$ atom on the $\mathrm{C}_{3} \mathrm{H}_{8}: \mathrm{O}_{2}$ ratio for $\mathrm{VO}_{x} / \mathrm{Al}_{2} \mathrm{O}_{3}$ catalysts during propane $\mathrm{ODH}$ [filled symbols, $\mathrm{C}_{3} \mathrm{H}_{8}$ dependence (1.0-16 $\mathrm{kPa} \mathrm{C}_{3} \mathrm{H}_{8}$, $4.0 \mathrm{kPa} \mathrm{O}$, balance $\mathrm{Ar}, 603 \mathrm{~K}$ ); open symbols, $\mathrm{O}_{2}$ dependence (4.0 $\mathrm{kPa} \mathrm{C}_{3} \mathrm{H}_{8}, 1.0-16 \mathrm{kPa} \mathrm{O}_{2}$, balance $\mathrm{Ar}, 603 \mathrm{~K}$ ); diamonds, $3.5 \mathrm{wt} \%$ $\mathrm{V}_{2} \mathrm{O}_{5} / \mathrm{Al}_{2} \mathrm{O}_{3}\left(2.3 \mathrm{~V} \mathrm{~nm}^{-2}\right)$; squares, $10 \mathrm{wt} \% \mathrm{~V}_{2} \mathrm{O}_{5} / \mathrm{Al}_{2} \mathrm{O}_{3}\left(8.0 \mathrm{~V} \mathrm{~nm}^{-2}\right)$; triangles, $30 \mathrm{wt} \% \mathrm{~V}_{2} \mathrm{O}_{5} / \mathrm{Al}_{2} \mathrm{O}_{3}\left(34 \mathrm{~V} \mathrm{~nm}^{-2}\right)$; filled circles are $\mathrm{C}_{3} \mathrm{H}_{8}$ dependence $\left(8.0 \mathrm{kPa} \mathrm{O}_{2}, 1.0-12 \mathrm{kPa} \mathrm{O}_{2}\right.$, balance $\left.\mathrm{Ar}, 603 \mathrm{~K}\right)$ for 10 wt $\% \mathrm{~V}_{2} \mathrm{O}_{5} / \mathrm{Al}_{2} \mathrm{O}_{3}\left(8.0 \mathrm{~V} \mathrm{~nm}^{-2}\right)$ ]. Adapted from ref 20 .

reduced centers reduces to one nonlinear differential equation ${ }^{31}$

$$
\frac{\mathrm{d}\left(n_{\mathrm{r}}\right)}{\mathrm{d} \tau}=\frac{\mathrm{d}(2 \phi)}{\mathrm{d} \tau}=2 \lambda_{2}+\left(1+\lambda_{1}\right)-\epsilon_{4} \frac{\left[\mathrm{O}_{2}\right]}{\left[\mathrm{C}_{3} \mathrm{H}_{8}\right]}(2 \phi)^{2}
$$

with the solution:

$$
\begin{gathered}
n_{\mathrm{r}}=\left(\frac{a}{b_{2}}\right)^{1 / 2\left(1-C_{1,2} \mathrm{e}^{-2 \tau \sqrt{a b_{2}}}\right)} \frac{\left(1+C_{1,2} \mathrm{e}^{-2 \tau \sqrt{a b_{2}}}\right)}{C_{1,2}=\frac{n_{\mathrm{r}}^{\mathrm{SS} 2}-n_{\mathrm{r}}^{\mathrm{SS} 1}}{n_{\mathrm{r}}^{\mathrm{SS} 2}+n_{\mathrm{r}}^{\mathrm{SS} 1}}}
\end{gathered}
$$

where $a=2 \lambda_{2}+\left(1+\lambda_{1}\right), b_{2}=\epsilon_{4}\left[\mathrm{O}_{2}\right] /\left[\mathrm{C}_{3} \mathrm{H}_{8}\right]$ evaluated at the reactant concentrations prevalent during the transient, and $n_{\mathrm{r}}^{\mathrm{SS} i}$ is the value of $n_{\mathrm{r}}$ at steady-state either at the start of the transient, $i=1$, or at the end, $i=2 .{ }^{31}$

At steady-state, the surface concentration of reduced centers, $n_{\mathrm{r}}^{\text {ss }}$, is given by:

$$
n_{\mathrm{r}}^{\mathrm{ss}}=2 \phi=\left(\frac{2 \lambda_{2}+\left(1+\lambda_{1}\right)}{\epsilon_{4}} \frac{\left[\mathrm{C}_{3} \mathrm{H}_{8}\right]}{\left[\mathrm{O}_{2}\right]}\right)^{0.5}
$$

Equation 13 predicts that for each catalyst, $n_{\mathrm{r}}^{\text {ss }}$ only depends on $\left(\left[\mathrm{C}_{3} \mathrm{H}_{8}\right] /\left[\mathrm{O}_{2}\right]\right)^{0.5}$. Assuming $\lambda_{1}$ and $\lambda_{2}$ to be independent of feed composition, $\epsilon_{4}$ can be determined for each catalyst from a fit of eq 13 to a plot of $n_{\mathrm{r}}^{\text {ss }}$ versus $\left(\left[\mathrm{C}_{3} \mathrm{H}_{8}\right] /\left[\mathrm{O}_{2}\right]\right)^{0.5}$ data, as shown in Figure 5. The values of $\epsilon_{4}$ determined in this manner are given in Table 2 for each catalyst.
TABLE 2: Values of $\epsilon_{4}$ Obtained from Steady-State Propane ODH Experiments ${ }^{20, a}$

\begin{tabular}{cr}
\hline catalyst $(\mathrm{wt} \%$ & \\
$\mathrm{V}_{2} \mathrm{O}_{5}$ on $\left.\mathrm{Al}_{2} \mathrm{O}_{3}\right)$ & $\epsilon_{4}{ }^{b}$ \\
\hline 3.5 & 101000 \\
10 & 1900 \\
30 & 1700
\end{tabular}

${ }^{a} 603 \mathrm{~K}, 1.0-16 \mathrm{kPa} \mathrm{C}_{3} \mathrm{H}_{8}, 1.0-16 \mathrm{kPa} \mathrm{O}_{2}$, balance He.

TABLE 3: Comparison of Propane ODH Rate Constants Obtained from UV-Visible Transient Data ${ }^{a}$ with Those Obtained from Steady-State Kinetic Experiments ${ }^{2} a$

\begin{tabular}{cccccc}
\hline $\begin{array}{c}\text { catalyst } \\
\left(\mathrm{wt}_{0} \mathrm{~V}_{2} \mathrm{O}_{5}\right. \\
\left.\text { on } \mathrm{Al}_{2} \mathrm{O}_{3}\right)\end{array}$ & $\begin{array}{c}\mathrm{V} \text { surface } \\
\text { density } \\
\left(\mathrm{V} \mathrm{nm}^{-2}\right)\end{array}$ & $\begin{array}{c}k_{5}{ }^{b} \\
{\left[\mathrm{~cm}^{3}(\mathrm{~mol} \mathrm{~s}\right.} \\
\left.\text { active site })^{-1}\right]\end{array}$ & $\begin{array}{c}K_{1} k_{2}{ }^{b} \\
{\left[\mathrm{~cm}^{3}\left(\mathrm{~mol} \mathrm{~s}^{2}\right.\right.} \\
\left.\text { active site })^{-1}\right]\end{array}$ & $\begin{array}{c}K_{1} k_{2} c, d \\
{\left[\mathrm{~cm}^{3}\left(\mathrm{~mol} \mathrm{~s}_{\mathrm{s}}\right)^{-1}\right]}\end{array}$ & $\begin{array}{c}\mathrm{V}_{\mathrm{s}, \text { cat }} / \\
\mathrm{V}_{\mathrm{s}}{ }^{d, e}\end{array}$ \\
\hline 3.5 & 2.3 & $3.4 \times 10^{6}$ & 34 & 25 & 0.71 \\
10 & 8.0 & $5.9 \times 10^{5}$ & 310 & 180 & 0.58 \\
30 & 34 & $4.6 \times 10^{5}$ & 280 & 190 & 0.63
\end{tabular}

${ }^{a} 603 \mathrm{~K}, 14 \mathrm{kPa} \mathrm{C}_{3} \mathrm{H}_{8}, 1.7 \mathrm{kPa} \mathrm{O}_{2}$, balance He. ${ }^{b}$ Results from UVvisible transient experiments. ${ }^{c}$ Results from steady-state propane $\mathrm{ODH}$ experiments. ${ }^{2}{ }^{d} \mathrm{~V}_{\mathrm{s}}$ represents surface vanadia, assuming that a maximum of $7.5 \mathrm{~V} \mathrm{~nm}^{-2}$ are exposed. ${ }^{e} \mathrm{~V}_{\mathrm{s}, \text { cat }}$ represents catalytically relevant surface vanadia.

The transient-response data obtained for each catalyst were fitted to the numerical model solution of eq 10 by adjusting the value of $K_{1} k_{2}$, assuming the value of $\epsilon_{4}=k_{5} / k_{2} K_{1}$ to be that obtained from steady-state data (see Table 2). The results of the simplified model are compared with experimental data in Figures $2-4$, for $3.5,10$, and $30 \mathrm{wt} \% \mathrm{~V}_{2} \mathrm{O}_{5} / \mathrm{Al}_{2} \mathrm{O}_{3}$, respectively. The ordinate in these plots is the normalized extent of reduction, $n_{\mathrm{r}}^{*}$, which is given by:

$$
n_{\mathrm{r}} *=\frac{\left(n_{\mathrm{r}}-n_{\mathrm{r}}^{\mathrm{SS} 1}\right)}{\left(n_{\mathrm{r}}^{\mathrm{SS} 2}-n_{\mathrm{r}}^{\mathrm{SS} 1}\right)}
$$

In eq $14, n_{\mathrm{r}}^{\mathrm{SS} 1}$ is the extent of reduction at steady-state immediately before a step change in inlet concentration, and $n_{\mathrm{r}}^{\mathrm{SS} 2}$ is the steady-state extent of reduction reached at the end of the imposed transient. The dark lines in Figures 2-4 represent experimental data, and the lighter lines represent model predictions. The leftmost columns in Figures 2-4 (labeled a-e) show experiments in which $\mathrm{C}_{3} \mathrm{H}_{8}$ partial pressure was varied at constant $\mathrm{O}_{2}$ pressure. The rightmost columns (labeled $\mathrm{f}-\mathrm{j}$ ) contain results of varying $\mathrm{O}_{2}$ at constant $\mathrm{C}_{3} \mathrm{H}_{8}$ partial pressure.

This single-parameter model accurately describes transient data at short times but becomes less accurate at longer times (Figures 2-4), suggesting that different types of surface sites with a range of turnover frequencies may be involved in the reaction, as expected for surfaces with $\mathrm{V}$ atoms in various geometries (e.g., edges and plateaus). In addition, the model tends to underestimate the initial slope at low $\mathrm{C}_{3} \mathrm{H}_{8}$ and $\mathrm{O}_{2}$ partial pressures and to overestimate the slope at high $\mathrm{C}_{3} \mathrm{H}_{8}$ and $\mathrm{O}_{2}$ partial pressures. No explanation for this behavior can be given at this time.

Table 3 shows the rate parameters obtained from this transient model. The values of $K_{1} k_{2}$ obtained from these data increase with increasing vanadia surface density in a manner similar to that observed for the $K_{1} k_{2}$ values obtained from steady-state rate data. ${ }^{29,30}$ As discussed previously, ${ }^{20,29,30}$ this pattern is attributable to the greater reducibility of oxide domains as they evolve from monovanadate to two-dimensional polyvanadate structures with increasing V surface density. More-reducible catalysts are able to stabilize most effectively the transition states 
required for $\mathrm{C}-\mathrm{H}$ bond activation, which in turn require delocalization of electron density by vanadium centers.

The rate coefficient for reoxidation of catalytically active sites is large $\left(\sim 10^{6} \mathrm{~cm}^{3} \mathrm{~mol}^{-1} \mathrm{~s}^{-1}\right)$, but decreases in magnitude with increasing vanadia surface density. It is also evident that $k_{5}$ is significantly larger than $K_{1} k_{2}$, consistent with the low extent of reduction during steady-state catalysis. We also note that for equal driving forces $\left(\left[\mathrm{O}_{2}\right]=\left[\mathrm{C}_{3} \mathrm{H}_{8}\right]\right.$ and $\left.[*]=\left[\mathrm{O}^{*}\right]\right)$, the rate of reoxidation $\left(r_{\mathrm{Ox}}=k_{5}\left[\mathrm{O}_{2}\right][*]^{2} /[\mathrm{L}]\right)$ is about $10^{3}$ larger than the rate of reduction $\left(\mathrm{r}_{\mathrm{Red}}=K_{1} k_{2}\left[\mathrm{C}_{3} \mathrm{H}_{8}\right]\left[\mathrm{O}^{*}\right]^{2} /[\mathrm{L}]\right)$ for the range of $\mathrm{O}_{2}$ and $\mathrm{C}_{3} \mathrm{H}_{8}$ partial pressures used in this investigation. The decrease in the value of $k_{5}$ with increasing $\mathrm{V}$ surface density is consistent with the observed changes in $\epsilon_{4}$ and $K_{1} k_{2}$. This suggests that the activation barrier to reoxidation of reduced vanadia species in isolated vanadate or small polyvanadate species is lower that than that for larger polyvanadate species.

Table 3 compares values of $K_{1} k_{2}$ with those obtained from steady-state kinetic analysis. ${ }^{2,3}$ For the analysis of transientresponse data, it is not necessary to measure independently the number of active surface $\mathrm{V}$ atoms in order to calculate an intrinsic rate parameter per active site. Consequently, the value of $K_{1} k_{2}$ determined from the UV-visible results directly reflects the reactivity of active sites participating in the reaction. In contrast, measured steady-state $\mathrm{ODH}$ rates are normalized by the number of surface $\mathrm{V}$ atoms, ${ }^{20}$ which may not accurately represent those accessible or active for catalytic reactions. In estimating steady-state turnover rates, it was assumed that for $\mathrm{V}$ surface densities of $7.5 \mathrm{~V} \mathrm{~nm}^{-2}$ or below (the value for a polyvanadate monolayer), all $\mathrm{V}$ centers were accessible to reactants. For $\mathrm{V}$ surface densities greater than $7.5 \mathrm{~V} \mathrm{~nm}^{-2}$, it was assumed that the density of $\mathrm{V}$ sites available for catalysis was equivalent to one monolayer of polyvanadate species because excess $\mathrm{VO}_{x}$ species tend to form large $\mathrm{V}_{2} \mathrm{O}_{5}$ clusters that do not contribute significant additional VO surface area. Dividing the value of $K_{1} k_{2}$ obtained from the transient-response experiment by that obtained from steady-state experiments provides an estimate of the fraction of accessible $\mathrm{V}$ centers that are active for propane $\mathrm{ODH}$ reactions at the conditions of our experiments. These fractions are reported in the last column of Table 3; they range from 0.71 in $3.5 \mathrm{wt} \% \mathrm{~V}_{2} \mathrm{O}_{5} / \mathrm{Al}_{2} \mathrm{O}_{3}$ to $\sim 0.60$ in 10 and 30 wt $\% \mathrm{~V}_{2} \mathrm{O}_{5} / \mathrm{Al}_{2} \mathrm{O}_{3}$. Thus, if the accessibility assumptions used in estimating steady-states are accurate, most, but not all of the accessible $\mathrm{V}$ atoms are active in $\mathrm{ODH}$ reactions. An alternate possibility is that only $71 \%$ of $\mathrm{V}$ atoms in $3.5 \mathrm{wt} \% \mathrm{~V}_{2} \mathrm{O}_{5} / \mathrm{Al}_{2} \mathrm{O}_{3}$ are accessible and thus active, as a result of the incipient formation of three-dimensional $\mathrm{V}_{2} \mathrm{O}_{5}$ clusters with a fraction of $\mathrm{V}$ species in their inaccessible bulk. Similarly, for 10 and $30 \mathrm{wt} \% \mathrm{~V}_{2} \mathrm{O}_{5} / \mathrm{Al}_{2} \mathrm{O}_{3}$ samples, it is possible that only a fraction of the support surface is covered by a two-dimensional polyvanadate monolayer and that nucleation of some $\mathrm{V}_{2} \mathrm{O}_{5}$ clusters occurs at surface densities below those calculated from geometric arguments for a theoretical polyvanadate monolayer.

\section{Conclusions}

In situ UV-visible spectroscopy can be used to follow the dynamics of catalyst reduction and oxidation during the oxidative dehydrogenation of propane over alumina-supported vanadia. The rate constant for vanadia reduction obtained from an analysis of the transient-response, UV-visible data can be compared with the same rate constant obtained from an analysis of steady-state kinetic rate data to estimate the fraction of the exposed vanadia that is catalytically active. This fraction lies between 60 and $70 \%$, suggesting that some of the surface V atoms are either inaccessible for propane ODH or are not active catalytically. The rate coefficient for vanadia reoxidation is $3-5$ orders of magnitude faster than that for reduction, and consequently, only a small fraction of the catalytically active $\mathrm{V}$ sites is reduced under steady-state conditions.

Acknowledgment. The authors wish to thank Nick Ohler for providing the Mathematica program used to model the experimental data and to determine the global minima. This work was supported by the Director, Office of Basic Energy Sciences, Chemical Sciences Division of the U.S. Department of Energy under Contract DE-AC03-76SF00098.

\section{References and Notes}

(1) Chen, K. D.; Khodakov, A.; Yang, J.; Bell, A. T.; Iglesia, E. J. Catal. 1999, 186, 325.

(2) Argyle, M. D.; Chen, K. D.; Bell, A. T.; Iglesia, E. J. Catal. 2002, $208,139$.

(3) Khodakov, A.; Olthof, B.; Bell, A. T.; Iglesia, E. J. Catal. 1999, $181,205$.

(4) Olthof, B.; Khodakov, A.; Bell, A. T.; Iglesia, E. J. Phys. Chem. B 2000, 104, 1516.

(5) Eon, J. G.; Olier, R.; Volta, J. C. J. Catal. 1994, 145, 318.

(6) Vuurman, M. A.; Wachs, I. E. J. Phys. Chem. 1992, 96, 5008.

(7) Weber, R. S. J. Catal. 1995, 151, 470.

(8) Brus, L. E. J. Chem. Phys. 1984, 80, 4403.

(9) Gao, X.; Jehng, J. M.; Wachs, I. E. J. Catal. 2002, 209, 43.

(10) Puurunen, R. L.; Beheydt, B. G.; Weckhuysen, B. M. J. Catal. 2001, 204, 253.

(11) Gao, X.; Bare, S. R.; Fierro, J. L. G.; Wachs, I. E. J. Phys. Chem $B$ 1999, 103, 618 .

(12) Gao, X.; BaZares, M. A.; Wachs, I. E. J. Catal. 1999, 188, 325

(13) Gao, X.; Bare, S. R.; Weckhuysen, B. M.; Wachs, I. E. J. Phys. Chem. B 1998, 102, 10842 .

(14) Wei, D.; Wang, H.; Feng, X.; Chueh, W.; Ravikovitch, P. Lyubovsky, M.; Li, C.; Takeguchi, T.; Haller, G. L. J. Phys. Chem. B 1999, $103,2113$.

(15) Melsheimer, J.; Mahmoud, S. S.; Mestl, G.; Schlögl, R. Catal. Lett. 1999, 60, 103.

(16) Weckhuysen, B. M. Chem. Commun. 2002, 97.

(17) Weckhuysen, B. M.; Schoonheydt, R. A. Catal. Today 1999, 49, 441.

(18) Brückner, A. Chem. Commun. 2001, 2122.

(19) Argyle, M. D.; Chen, K. D.; Resini, C.; Krebs, C.; Bell, A. T.; Iglesia, E. Chem. Commun. 2003, 2082.

(20) Argyle, M. D.; Chen, K. D.; Resini, C.; Krebs, C.; Bell, A. T.; Iglesia, E. J. Phys. Chem. B 2004, 108, 2345.

(21) Weckhuysen, B. M.; Verberckmoes, A. A.; Debaere, J.; Ooms, K.; Langhans, I.; Schoonheydt, R. A. J. Catal. 2000, 151, 115.

(22) Bensalem, A.; Weckhuysen, B. M.; Schoonheydt, R. A. J. Phys. Chem. B 1997, 101, 2824.

(23) Grubert, G.; Rathousky, J.; Schulz-Ekloff, G.; Wark, M.; Zukal, A. Microporous Mesoporous Mater. 1998, 22, 225.

(24) Kung, H. H. Adv. Catal. 1994, 40, 1.

(25) Mamedov, E. A.; Cortés Corberán, V. Appl. Catal. A 1995, 127, 1 .

(26) Albonetti, S.; Cavani, F.; Trifirb, F. Catal. Rev.-Sci. Eng. 1996, 38,413 .

(27) Blasco, T.; López Nieto, J. M. Appl. Catal. A 1997, 157, 117.

(28) BaZares, M. A. Catal. Today 1999, 51, 319.

(29) Chen, K. D.; Bell, A. T.; Iglesia, E. J. Phys. Chem. B 2000, 104, 1292.

(30) Chen, K. D.; Iglesia, E.; Bell, A. T. J. Catal. 2001, 192, 197.

(31) Argyle, M. D. Ph.D. Dissertation, University of California, Berkeley, CA, 2003.

(32) Argyle, M. D.; Chen, K. D.; Bell, A. T.; Iglesia, E. J. Phys. Chem B 2002, 106, 5421 . 